\title{
Evaluating Strategic Leadership based on the Method of Fuzzy Analytic Network Process
}

\author{
Fei $\mathrm{Li}^{1, *}$, Lijun $\mathrm{Liu}^{2}$ and Bao Xi $i^{1}$ \\ ${ }^{1}$ Harbin Institute of Technology, Harbin, 150001, P. R. China \\ ${ }^{2}$ Beijing Institute of Technology, Beijing, 100081, P. R. China
}

Received: 5 Jul. 2013, Revised: 9 Nov. 2013, Accepted: 10 Nov. 2013

Published online: 1 May. 2014

\begin{abstract}
We apply the method of Fuzzy Analytic Network Process (ANP-Fuzzy) to evaluate strategic leadership, because its indexes are complex, inter-relationship, and fuzzy. First, construct indexes system of strategic leadership, which constitutes of personal abilities and organizational abilities. Second, interpret the fitness of ANP-Fuzzy for strategic leadership and the method's implication steps of ANP structure, pairwise comparisons and priority vectors, super matrix formation and transformation, and fuzzy evaluation. Final, design ANP structure of strategic leadership, calculate priorities, and analyse empirically strategic leadership of candidates for promotion by fuzzy evaluation. Results show that the method is feasible, because it can get not only the whole status of strategic leadership but also of personal abilities and organizational abilities, which gives significant decision support.
\end{abstract}

Keywords: Fuzzy Analytic Network Process (ANP-Fuzzy), evaluate, strategic leadership

\section{Introduction}

Competition in the ages of global economy is more complex, changing more quickly, more unpredictable, brings more and greater new challenges to organization management, which means more threats and simultaneously more opportunities. Strategic leadership plays vital role for organizations dealing with variations and retaining competitive advantages[1,2]. For organizations, effective strategic leadership can help them adapt better to new environment[3], so that they may improve performance and enhance competitive power in turbulent environments. And evaluating strategic leadership of persons are significant for choosing leaders or understanding their advantages and disadvantages of strategic leadership to mend the capacity, organizations to adapt themselves better to environment.

There is comparatively a rich body of literature on strategic leadership concept or type[4,5,6], and its effect or path[7,8,9], while research on assessing strategic leadership is scant. Drawing on related literature, we discuss the concept of strategic leadership and construct the indexes system. Then describe the method of fuzzy analytic network process (ANP-Fuzzy), present the empirical analysis procedure and conclude with discussion about ANP-Fuzzy evaluating strategic leadership.

\section{Indexes System}

Strategic leadership focuses on executives who have overall responsibility for an organization[10]. As the top leaders of organization, they must establish a strategy by properly analysing the interior and exterior environment in which the organization exists, implement the right strategy at the right time, evaluate and act the appropriate behavior that is suitable for the current environment. The activities associated with strategic leadership means the leaders should have some strategic qualities that related with personal style[11]. Especially in the circumstances where the change is experience rapidly and the completion lasts around the world, strategic leadership ability becomes a necessity.[9]

Basic responsibility of the top leaders is all about the existence of the organization and maintenance of its competitive advantage by definition. So forward-looking, directive ability and features matter.[12]That is, strategic leaders should have not only personal abilities but also organizational abilities.[13,14]

\footnotetext{
*Corresponding author e-mail: thanksall@ hit.edu.cn
} 
The personal abilities show that the essence of strategic leadership is the creation and maintenance of strategic thinking, absorptive capacity, adaptive capacity and managerial wisdom. Strategic thinking refers to thinking in a long run and not content with the existing conditions[15]. If the top leader has not a competence in strategic thinking, they would be unable even to see the need to change direction[16]. Absorptive capacity refers to the ability to learn, mainly involving the capacity to recognize new information, assimilate it and apply it to new circumstance. Adaptive capacity refers to the ability to change. In turbulent environment, organizational success depends upon strategic flexibility, because it allows for the attainment of performance goal and the options to take advantage of future opportunities. And the strategic flexibility derives from the top leaders, so they must have ability to be adapted to change. Wisdom refers to abilities to come up with ideas, make a decision, influence others or balance interest, and so on. In a word, wisdom is the capacity to take the right action at the right time and place.

The organizational abilities include five indexes as follows. Strategic focusing[17] is the ability to be strategically oriented, making the leader link visions to daily work, assuring strategy objective. On that base, leaders should turn strategy into operational terms[18], which means identifying some projects that need to be carried out to move the organization toward state that strategy describes. At the same time, leaders should pay more attention to aligning individuals to the organization through shared values[3], which is the way to build connection between vision and action by influencing others. Strategy generally meaning vision and direction, demands appropriate moment for strategic change in organization, called effective opportunity points. The point is the key to strategy implement. In addition, it's important for organization to develop sustainably, so the top leader should have the ability to develop organizational core competencies[19].

On the basis of relevant research the evaluation index system is designed (see Table 1).

Table 1: Index system

\begin{tabular}{c|c}
\hline \multicolumn{2}{c}{ Strategic leadership $(P)$} \\
\hline Personal & strategic thinking $\left(P_{11}\right)$ \\
abilities $\left(P_{1}\right)$ & absorptive capacity $\left(P_{12}\right)$ \\
& adaptive capacity $\left(P_{13}\right)$ \\
& managerial wisdom $\left(P_{14}\right)$ \\
\hline & strategic focusing $\left(P_{21}\right)$ \\
Organizational & turning strategy into action $\left(P_{22}\right)$ \\
abilities $\left(P_{2}\right)$ & aligning individuals \\
& to the organization $\left(P_{23}\right)$ \\
& effective opportunity points $\left(P_{24}\right)$ \\
& developing organizational \\
& core competencies $\left(P_{25}\right)$ \\
\hline
\end{tabular}

\section{The Method of ANP-Fuzzy}

\subsection{Fitness of ANP-Fuzzy for Strategic Leaders- hip}

Because of multi-dimensions, strategic leadership evaluation indexes system is a complex decision system. Not only are there different indicators, but also there exist inter-relationships among indicators. We choose ANP-Fuzzy to evaluation strategic leadership, which is one of multi-criteria decision techniques that are most appropriate for solving complex decision-making problems.

ANP-Fuzzy is a synthetic method to the alternative selection and justification problem by using the concept of analytic network process (ANP)and Fuzzy set theory. On the hand, the ANP allows for complex inter-relationships among decision levels and attributes. And its feedback approach is networks, in which the relationships between levels are not easily represented as higher or lower, dominant or subordinate, direct or indirect. The importance of the alternatives and the alternatives may have impact on each other. So ANP with net structure is more suitable for a complex system. And on the other hand, decision maker usually find that it is more confident to give interval judgements than fixed value judgements, because usually he is unable to explicit about his preferences due to the fuzzy nature of the comparison process.

\subsection{Implication Steps}

We evaluate strategic leadership with ANP-Fuzzy as following steps.

Step 1: ANP structure. ANP structure is made up of criteria level and network level. The former includes target and criteria level. The latter is a network where nodes respectively correspond to clusters. The elements in a cluster influence all the elements in another cluster. These relationships are represented by arcs with directions. Also the relationships among elements cluster can exist and be represented by a loop arc. Fig.1 shows the ANP structure.

Step 2: pairwise comparisons and priority vectors. Pairwise comparisons are made for interdependency among elements inside and outside clusters. Cluster weights are required to weight the supermarket at the next step, so clusters are also compared with each other. The relative importance values are determined with a sale of 1-9, where a score of 1 indicates equal importance between two elements and 9 represents the extreme importance of one element compared to the other one. Then a reciprocal value is assigned to the inverse comparison, so there is $a_{i j}=1 / a_{j i}$, and $a_{i j}$ denotes the importance of the ith element compared to the $j t h$ element. The eigenvector method is employed to obtain 

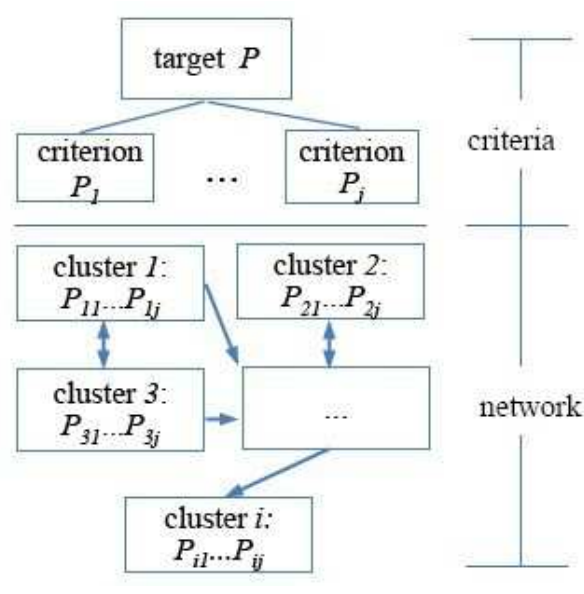

Fig. 1: ANP structure

local priority vectors for each pairwise comparison matrix.

Step 3: super matrix formation and transformation. The local priority vectors are entered into the appropriate columns of a super matrix, which is a partitioned matrix where each segment represents a relationship between two clusters. The super matrix of a system of two clusters is denoted as formulation (1):

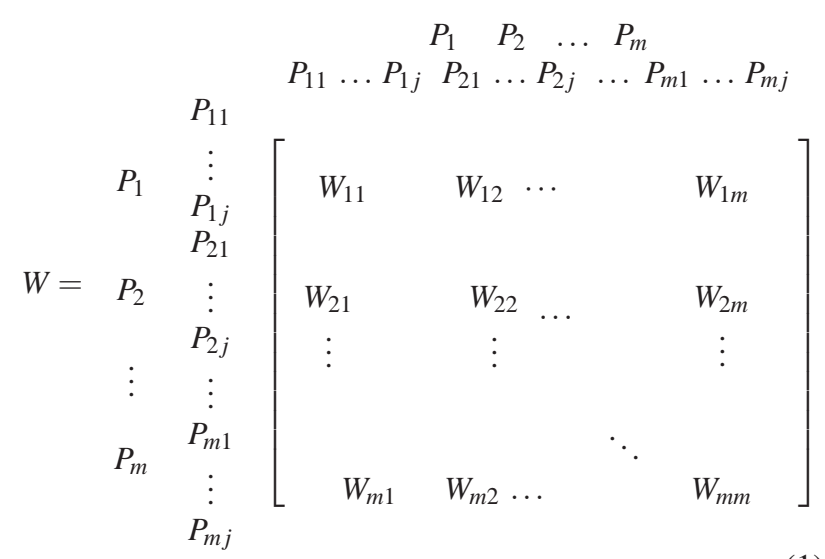

$P_{i}$ is the ith cluster $(k=1,2, \ldots, m)$ which has $j$ elements denoted as $P_{i 1}, \& P_{i 2}, \ldots, \& P_{i j}$. A matrix segment $W_{i j}$, represents a relationship between the ith cluster and the $j$ th cluster. Each column of $W_{i j}$ is a local priority vector obtained from the corresponding pairwise comparison, representing the importance of the elements in the ith cluster on an element in the $j t h$ cluster. If there is no relationship between clusters, the corresponding matrix segment is a zero matrix. The super matrix is transformed into the weighted super matrix, whose columns sum to one. Then the weighted super matrix is transformed into the limit super matrix to confirm priority of $P_{i j}$, shown in formulation (2):

$$
W^{\infty}=\lim _{i \rightarrow \infty}\left(\frac{1}{m}\right) \sum_{i=1}^{m} \overline{W_{i}}
$$

Where the column stochastic feature allows convergence to occur and the finial priorities of elements are found in the corresponding columns in it.

Step 4: Fuzzy evaluation. We obtain $p_{i}$ evaluation matrix through fuzzy linear transformation $p_{i j}$, as shown in formulation (3):

$$
r_{i j}=\frac{f_{i j}}{\sum_{j=1}^{n} f_{i j}}
$$

Where $f_{i j}$ denotes times that $P_{i j}$ is evaluated at one scale, and $r_{i j}$ is the membership degree corresponding with $P_{i j}$ scale evaluated. We can calculate the evaluation vector $B_{i}$ of $P_{i}$ according to $P_{i j}$ priorities and $P_{i}$ evaluation matrix. $B_{i}$ is denoted as following:

$$
\begin{aligned}
& B_{i}=W_{i j}{ }^{\circ} R_{j i} \\
& =\left(\omega_{i 1}, \omega_{i 2}, \ldots, \omega_{i j}\right)^{\circ}\left[\begin{array}{cccc}
r_{11} & r_{12} & \ldots & r_{1 t} \\
r_{21} & r_{22} & & r_{2 t} \\
\vdots & \ddots & \vdots \\
r_{j 1} & r_{j 2} & \cdots & r_{j t}
\end{array}\right] \\
& =\left(b_{i 1}, b_{i 2}, \ldots b_{i t}\right)
\end{aligned}
$$

Membership degree theory tell us that the scale corresponding to the max membership degree is the performance of $B_{i}$. According to $B_{i}$, we construct the total evaluation matrix $B$, as shown in formulation (5):

$$
B=\left[\begin{array}{c}
B_{1} \\
B_{2} \\
\vdots \\
B_{m}
\end{array}\right]=\left[\begin{array}{cccc}
b_{11} & b_{12} & \ldots & b_{1 t} \\
b_{21} & b_{22} & & b_{2 t} \\
\vdots & \ddots & \vdots \\
b_{j 1} & b_{j 2} & \cdots & b_{j t}
\end{array}\right]
$$

Then based on $W$ and $B$, the total evaluation vector $U$ can be obtained, as shown in formulation (6):

$$
U=W^{\circ} B=\left(u_{1}, u_{2}, \ldots, u_{l}, \ldots, u_{t}\right)
$$

Where the scale that the max $u_{l}$ is corresponding to is the leader's strategic leadership level.

\section{Empirical Analysis}

There is one state-enterprise, who wants to assess managers of departments for promotion. The promotion pays more attention to strategic leadership. We use ANP-Fuzzy to evaluation three candidates' strategic leadership. 

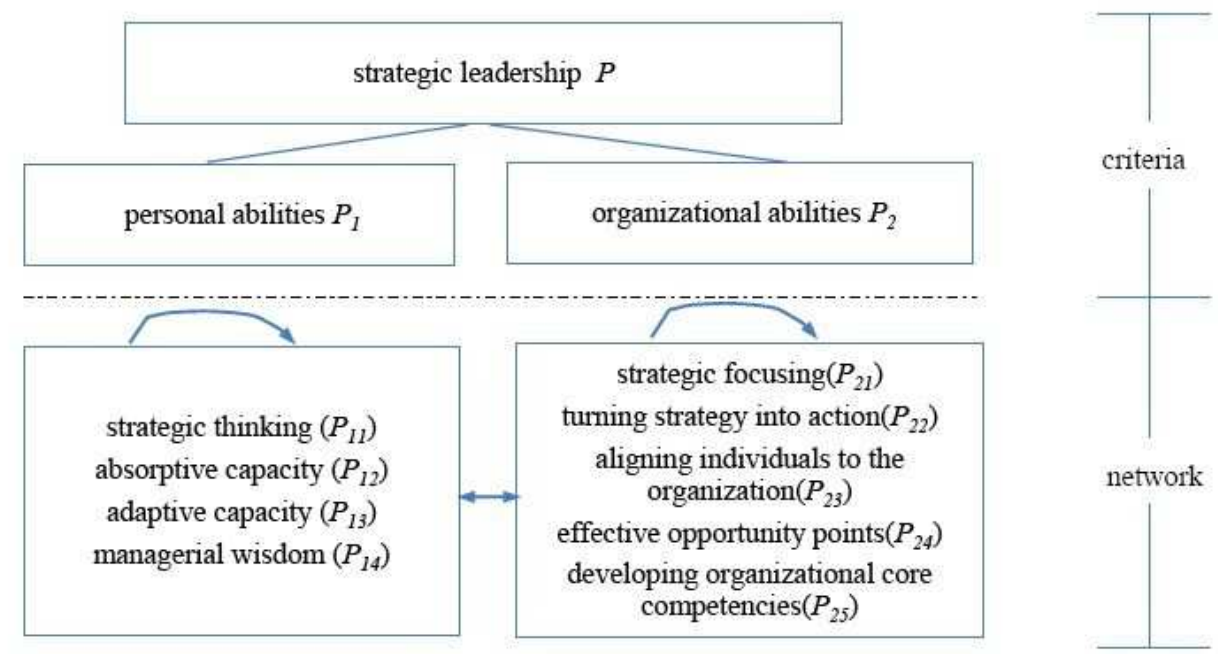

Fig. 2: ANP structure of strategic leadership

\subsection{Priorities}

First we construct ANP structure of strategic leadership according to its index system in Super Decisions. As shown in Fig.2.

The criteria include strategic leadership $P$, personal abilities $P_{1}$ and organizational abilities $P_{2}$. The network constitutes of nodes $P_{1 j}$ and $P_{2 j}$ respectively correspond to clusters $P_{1}$ and $P_{2}$. There exist three basic relationships between nodes of $P_{1 j}$, between nodes of $P_{2 j}$, and between clusters. The elements in cluster $P_{1}$ influence all the elements in cluster $P_{2}$. Second, invite related leaders, experts to score the index system of strategic leadership. In the ANP structure, evaluate the relationships between $P_{i j}$ in criteria $P_{i}$, and construct judgement matrix, for example Table 2. We use rule of nine, 1-9 mean one index

Table 2: Judgement matrix of $P_{1}$

\begin{tabular}{ccccc}
\hline Criterion $P_{1}$ & $P_{11}$ & $P_{12}$ & $P_{13}$ & $P_{14}$ \\
\hline$P_{11}$ & 1 & 4 & 3 & 2 \\
$P_{12}$ & $1 / 4$ & 1 & 3 & $1 / 2$ \\
$P_{13}$ & $1 / 3$ & $1 / 3$ & 1 & $1 / 3$ \\
$P_{14}$ & $1 / 2$ & 2 & 3 & 1 \\
\hline
\end{tabular}

has influence on other one from small to large. The final judgement matrix adopts the mean of all the scores. Its $C R$ is $0.032(<0.1)$, and that the matrix has rational consistence. In the similar way, the judgement matrix of $P_{2}$ and $P$. The $C R$ are respectively 0.019 and 0.057 . Then compute ANP super matrix, weighted super matrix and limit matrix. The limit matrix is convergent and single, so the column involves the finial priorities of elements:

$$
W=(0.63,0.37)
$$

$$
\begin{gathered}
W_{1}=(0.243,0.112,0.091,0.183) \\
W_{2}=(0.106,0.054,0.047,0.071,0.089)
\end{gathered}
$$

\subsection{Fuzzy Evaluation}

We choose related leaders and important followers to measure strategic leadership elements of candidates for promotion. Linguistic values, the mean of fuzzy numbers and measurement frequency of three candidates are shown in Table 3.

The next step is to construct an evaluation matrix (see $K_{11}$ ) according to measurement frequency. For example, the evaluation matrix of candidate $1\left(C_{1}\right)$ 's personal abilities can be denote as:

$$
R_{11}=\left[\begin{array}{cccccc}
0.000 & 0.667 & 0.333 & 0.000 & 0.000 \\
0.333 & 0.667 & 0.000 & 0.000 & 0.000 \\
0.000 & 1.000 & 0.000 & 0.000 & 0.000 \\
0.333 & 0.667 & 0.000 & 0.000 & 0.000
\end{array}\right]
$$

Then evaluation vector $B_{11}$ of $C_{1}$ 's personal abilities can be computed as follow:

$$
\begin{aligned}
& B_{11}=W_{1}^{\circ} R_{11}
\end{aligned}
$$

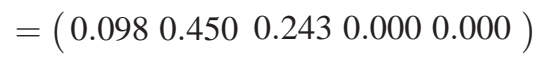

In the same way we can get other vectors, shown as table 4.

Table 4 shows that the strategic leaderships of 3 candidates are all good. There in, personal abilities are all good, and organizational abilities of $C_{1}$ are better than others. Research outcomes shows that $C_{1}$ is appreciably good candidate. 
Table 3: Frequency of linguistic values

\begin{tabular}{|c|c|c|c|c|}
\hline \multicolumn{2}{|c|}{ Linguistic values } & Very good & Good & Better \\
\hline \multirow{9}{*}{$C_{1}$} & $P_{11}$ & 0 & 2 & 1 \\
\hline & $P_{12}$ & 1 & 2 & 0 \\
\hline & $P_{13}$ & 0 & 3 & 0 \\
\hline & $P_{14}$ & 1 & 2 & 0 \\
\hline & $P_{21}$ & 2 & 1 & 0 \\
\hline & $P_{22}$ & 1 & 1 & 1 \\
\hline & $P_{23}$ & 2 & 1 & 0 \\
\hline & $P_{24}$ & 1 & 2 & 0 \\
\hline & $P_{25}$ & 1 & 2 & 0 \\
\hline \multicolumn{2}{|c|}{ Linguistic values } & Very good & Good & Better \\
\hline \multirow{9}{*}{$C_{2}$} & $P_{11}$ & 0 & 2 & 1 \\
\hline & $P_{12}$ & 0 & 1 & 2 \\
\hline & $P_{13}$ & 0 & 1 & 2 \\
\hline & $P_{14}$ & 0 & 0 & 3 \\
\hline & $P_{21}$ & 0 & 1 & 2 \\
\hline & $P_{22}$ & 0 & 1 & 2 \\
\hline & $P_{23}$ & 0 & 1 & 2 \\
\hline & $P_{24}$ & 0 & 1 & 1 \\
\hline & $P_{25}$ & 0 & 1 & 2 \\
\hline \multicolumn{2}{|c|}{ Linguistic values } & Very good & Good & Better \\
\hline \multirow{9}{*}{$C_{3}$} & $P_{11}$ & 0 & 2 & 1 \\
\hline & $P_{12}$ & 0 & 1 & 2 \\
\hline & $P_{13}$ & 0 & 1 & 2 \\
\hline & $P_{14}$ & 0 & 0 & 3 \\
\hline & $P_{21}$ & 0 & 1 & 2 \\
\hline & $P_{22}$ & 0 & 1 & 2 \\
\hline & $P_{23}$ & 0 & 1 & 2 \\
\hline & $P_{24}$ & 0 & 1 & 1 \\
\hline & $P_{25}$ & 0 & 1 & 2 \\
\hline
\end{tabular}

Table 4: Results of evaluating strategic leadership

\begin{tabular}{|c|c|c|c|c|c|c|c|}
\hline \multirow{2}{*}{$\begin{array}{l}\text { Can- } \\
\text { did- } \\
\text { ates }\end{array}$} & \multirow{2}{*}{$\begin{array}{l}\text { In- } \\
\text { dex }\end{array}$} & \multicolumn{5}{|c|}{ Evaluation vector } & \multirow{2}{*}{$\begin{array}{l}\text { Res- } \\
\text { ults }\end{array}$} \\
\hline & & $\begin{array}{l}\text { Very } \\
\text { good }\end{array}$ & Good & Better & $\begin{array}{l}\text { Gen- } \\
\text { eral }\end{array}$ & $\begin{array}{l}\text { Not } \\
\text { good }\end{array}$ & \\
\hline \multirow{4}{*}{$C_{1}$} & $P$ & .126 & .349 & .160 & 0.0 & 0.0 & good \\
\hline & $P_{1}$ & .098 & .450 & .243 & 0.0 & 0.0 & good \\
\hline & $P_{2}$ & .175 & .175 & .018 & 0.0 & 0.0 & Very \\
\hline & & & & & & & good \\
\hline \multirow{3}{*}{$C_{2}$} & $P$ & .189 & .350 & .009 & 0.0 & 0.0 & good \\
\hline & $P_{1}$ & .229 & .400 & 0.0 & 0.0 & 0.0 & good \\
\hline & $P_{2}$ & .122 & .221 & .024 & 0.0 & 0.0 & good \\
\hline \multirow{3}{*}{$C_{3}$} & $P$ & .190 & .344 & 0.0 & 0.0 & 0.0 & good \\
\hline & $P_{1}$ & .223 & 406 & 0.0 & 0.0 & 0.0 & good \\
\hline & $P_{2}$ & .134 & .238 & 0.0 & 0.0 & 0.0 & good \\
\hline
\end{tabular}

\section{Conclusion}

Strategic leadership is a key ability of a leader for organization in dynamic and changeable environment, so it's important and necessary to evaluate strategic leadership.

We construct the indexes system, constituting of personal abilities and organizational abilities, where the former includes strategic thinking, absorptive capacity, adaptive capacity and managerial, and the letter includes strategic focusing, turning strategy into action, aligning individuals to the organization, effective opportunity points and developing organizational core competencies. Because of the complex of strategic leadership, we choose the method of ANP-Fuzzy to evaluate it: calculates priorities of elements by ANP and computing strategic leadership evaluation outcomes by fuzzy. Then we test the method by empirical research, and results show that the method can not only obtain the whole outcome of strategic leadership, but also show meanwhile details in aspects of personal abilities and organizational abilities, which provide significant decision support.

\section{Acknowledgement}

The first author acknowledges the financial support by the Project of Post Doctor Support Fund of Heilongjiang Province of China and the Key Project of National Social Science Fund of China (No.11AGL003)

\section{References}

[1] Storey J. What Next for Strategic-Level Leadership Research. Leadership, 1, 89-104 (2005).

[2] Memon M A, Mangi R A, Chandan Lsl R. Human Capital a Source of Competitive Advantage Idea for Strategic Leadership. Australian Journal of Basic \& Applied Sciences, 3, 4182-4189 (2009).

[3] Paul J.H. Schoemaker, Steve Krupp, Strategic leadership: the essential skills.Harvard Business Review, 91, 131-134 (2013).

[4] Davis B, Davies B J, The nature and dimensions of strategic leadership. International Studies in Educational Administration (Commonwealth Council for Educational Administration \& Management), 38, 5-21 (2010).

[5] Hosmer L R T, The importance of strategic leadership, The Journal of Business Strategy, 3, 47-57 (1982).

[6] Hitt M A, Duane R., The essence of strategic leadership: managing human and social capital, Journal of Leadership \& Organizational Studies, 9, 3-14 (2002).

[7] Finkelstein S, Hambrick D C. Strategic leadership: top executives and their effects on organizations[M]. West, Minneapolis: St. Paul, (1996).

[8] Elenkov D S, Judge W, Wright P. Strategic leadership and executive innovation influence: an international multi-cluster comparative study. Strategic Management Journal, 26, 665682 (2005).

[9] Sirmon DG. Hitt MA Ireland R.D. Managing firm resources in dynamic environments to create value: looking inside the black box. Academy of Management Review, 32, 273-292 (2007).

[10] Hambrick, D. C., \& Mason, P. A. (1984). Upper echelons: the organization as a reflection of its top managers. Academy of Management Review, 9, 193-206 (1984).

[11] Phipps Kelly,Spirituality and strategic leadership: the influence of spiritual beliefs on strategic decision making, Journal of Business Ethics, 106, 177-189 (2012). 
[12] Ulgen H, Mirze SK, Letmelerde Stratejik Yonetim, Stanbul: Literatr Yaynclk, (2004).

[13] Barbara J. Davies,Brent Davies, Strategic leadership, School Leadership and Management, 24, 28-38 (2004).

[14] Boal, Kimberly B., Hooijberb, Robert, Strategic leadership research: moving on, The Leadership Quarterly, 11, 514-549 (2000).

[15] Gavetti, Giovanni, The new psychology of strategic leadership. Harvard Business Review, 89, 118-125 (2011).

[16] Kurnia Wahjudono Denny Bernardus, Ellitan Lena, Otok Bambang Widjanarko,Confirmatory factor analysis on organization reputation, strategic leadership, and organization culture as a resources-based view. Journal of Management Research, 5, 260-268 (2013).

[17] Ballantyne Scott, Leadership decision-making utilizing a strategic focus to enhance global achievement, Journal of Management \& Marketing Research, 1, 1-6 (2012).

[18] Bucolo Sam, Wrigley Cara, Matthews Judy, Gaps in organizational leadership: linking strategic and operational activities through design-led propositions,Design Management Journal, 7, 18-28 (2012).

[19] Ireland R. Duane, Hitt Michael A., Achieving and maintaining strategic competitiveness in the 21st century: the role of strategic leadership, Academy of Management Executive, 19, 63-77 (2005).

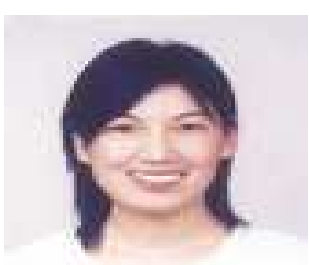

Fei $\mathbf{L i}$ received the $\mathrm{PhD}$ degree in Management Science from Harbin Institute of Technology, China in 2008. She is currently lecturer in Higher Education Research Institute, Harbin Institute of Technology. Her research interests are in the areas of leadership studies, talents science, learning science,higher education management and applied mathematics.

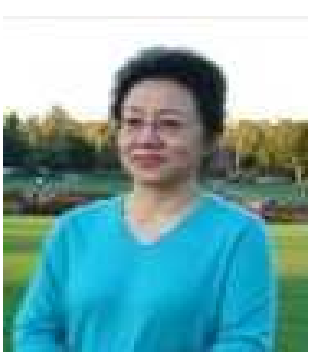

Lijun Liu received the $\mathrm{PhD}$ degree in Management Science from Beijing Institute of Technology, China in 2005. She is currently Associate Professor in Institute of Education, Beijing Institute of Technology, and is the director of Center for Innovation and Entrepreneurship education. Her research interests include knowledge innovation and entrepreneurship education, innovation management, scientific research management, teaching research, and higher education management.

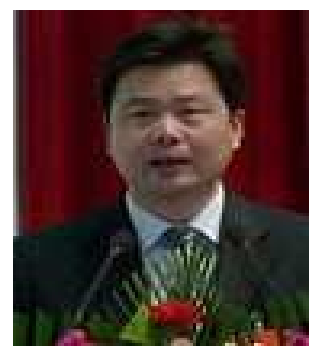

Bao $\mathbf{X i}$ received the $\mathrm{PhD}$ degree in Management Science from Harbin University of Civil Engineering and Architecture, China in 1999. He is currently Professor in Faculty of Humanities and Social Sciences, Dalian University of Technology. His research interests include civil disaster prevention and mitigation management, public policy behavior simulation, frustration management, and system analysis and design. 